\title{
Entre voos e pousos, uma cartografia de/em "Percy Jackson e o Ladrão de Raios"
}

\section{Between flights and landscapes, a cartograph by/in "Percy Jackson and the Lightning Thief"}

https://doi.org/10.34112/2317-0972a2021V39n81p47-61

\author{
Sabrina da Silva Gava ${ }^{1}$ \\ Giovana SCARELI ${ }^{2}$
}

RESUMO: Num movimento-reflexão, este texto relata a metodologia de pesquisa empregada em uma dissertação de mestrado que estudou a obra $O$ Ladrão de Raios a partir de três diferentes produções culturais: o livro, o filme e a graphic novel. Mais que apresentar os resultados de uma pesquisa que, de modo geral, busca observar como os mitos gregos são apropriados pela indústria cultural, este texto trata de apresentar os percursos e intensidades de uma cartografia movimentada por diferentes discursos e imagens - uma linha dentre tantas outras que deseja mostrar a experiência de duas pesquisadoras-cartógrafas na passagem de um pensamento arborescente para um pensamento rizomático, utilizando-se de voos, pousos e janelas atencionais.

Palavras-chave: O Ladrão de Raios; cartografia; educação visual.

ABSTRACT: In a movement-reflection, this text reports the methodology of research used in a master's thesis that studied the work "The Lightning Thief” from three different cultural productions: the book, the film and the graphic novel. More than presenting the results of a research that, in general, seeks to observe how the greek myths are appropriated by the cultural industry, this text tries to present the routes and intensities of a cartography

1. Instituto Federal de Educação, Ciência e Tecnologia do Sudeste de Minas Gerais, Barbacena, MG, Brasil.

2. Universidade Federal de São João del-Rei - UFSJ, São João del-Rei, MG, Brasil. 
moved by different discourses and images - a line of so many others that wants to show the experience of two researche-cartographers in the transition from arborescent thinking to rhizomatic thinking, using flights, inns and windows and practices.

KEYWORDS: The Lightning Thief; cartography; visual education.

\section{A CARTOGRAFIA COMO UM MODO PRÓPRIO E INVENTIVO DE PESQUISAR}

Serão possíveis outros modos de pesquisar para além daqueles que, normalmente, encontramos nos manuais de pesquisa e que são os mais utilizados na academia? Talvez, muitas pessoas sequer pensem nessa pergunta, assim como nós também não pensávamos. Sabíamos apenas que para se fazer uma pesquisa e esta ser válida era necessário ter um "problema", isto é, uma questão instigante sobre um objeto a ser investigado; uma "hipótese", resposta provável ao problema formulado e sujeita à verificação; e "objetivos" gerais e específicos, metas que se pretende atingir ao final da investigação. Sem sabermos, esse tipo de pensamento estava abrigado sob uma "grande árvore", que só no decorrer da pesquisa foi possível compreender melhor.

Essa "grande árvore", cujas extensas raízes estão firmemente fincadas no solo (as premissas verdadeiras) e cujo tronco consistente se ramifica em numerosos galhos (os saberes compartimentalizados), faz alusão ao pensamento arbóreo. Isto é, paradigmas que validam a ideia de que o saber parte de uma base comum e sólida para, depois, ser classificado e hierarquizado em outros ramos de conhecimento. Uma metáfora botânica, diz Sílvio Gallo (2013, p. 72-73), na qual o "paradigma arborescente representa uma concepção mecânica do conhecimento e da realidade, reproduzindo a fragmentação cartesiana do saber, resultado das concepções científicas modernas". Essa metáfora nos provoca e nos faz questionar: quais são as implicações dessa estrutura de conhecimento tradicional nas pesquisas acadêmicas?

A estrutura de conhecimento tradicional ou arbóreo se relaciona a um pensamento simplificador que é incapaz de conceber a conjunção do uno com o múltiplo: ou ele unifica abstratamente ao anular a diversidade, ou, ao contrário, justapõe a diversidade sem conceber a unidade - o que leva à patologia do saber que Morin denomina de "inteligência cega que destrói os conjuntos e as totalidades, isola todos os seus objetos do seu meio ambiente. Ela não pode conceber o elo inseparável entre o observador e a coisa observada" (2015, p. 12). O que, de certa forma, é muito incoerente com a complexa realidade em que vivemos e seus fenômenos. Isso porque, 
quando os observamos, acabamos por atuar sobre eles e somos, ao mesmo tempo, produtores e produtos da investigação; não coletamos dados, mas produzimos e interpretamos dados - o que nos leva a ponderar:

Ter um mundo às mãos é comprometer-se ética e politicamente no ato do conhecimento. É intervir sobre a realidade. É transformá-la para conhecê-la. Há uma dimensão da realidade em que ela se apresenta como processo de criação, como poiesis, o que faz com que, em um mesmo movimento, conhecê-la seja participar de seu processo de construção (KASTRUP, PASSOS, 2013, p. 264).

Essa visão rompe com o dualismo que separa sujeito/objeto, alma/corpo, mito/ razão, imaginário/real, falso/verdadeiro, natureza/cultura, ciência/arte, quantidade/qualidade, ordem/desordem, unidade/diversidade, dentre outros elementos que, em verdade, são dinâmicos e indeterminados.

Gilles Deleuze e Félix Guattari enxergam que a realidade é marcada por esse jogo de relações múltiplas, coexistentes e, de certa forma, complementares. Artífices do conceito de rizoma, que é a base da cartografia, consideram que o pensamento rizomático surge por entre as fissuras do pensamento arborescente.

O que conta é que a árvore-raiz e o rizoma-canal não se opõem como dois modelos: um [a árvore] age como modelo e como decalque transcendente, mesmo que engendre suas próprias fugas; o outro [o rizoma] age como processo imanente que reverte $\mathrm{o}$ modelo e esboça um mapa, mesmo que constitua suas próprias hierarquias, e inclusive ele suscite um canal despótico (DELEUZE; GUATTARI, 1995, p. 30-31).

É esse modo de assimilar o conhecimento que nos permite conceber a cartografia como linha de fuga, como um outro modo de pesquisar para além daquele instituído pelo paradigma predominante na academia. Denominada também de esquizoanálise, pragmática e micropolítica, a cartografia "pode se apresentar enquanto uma prática singular de pesquisa e de análise. $\mathrm{O}$ conceito, inicialmente retirado da geografia, é transposto para os campos da filosofia, política e subjetividade" (COSTA, 2014, p. 69). Assim, é antes um "estilo" de se fazer pesquisa do que propriamente um método, um processo organizado, lógico e sistemático de pesquisa, haja vista que consiste na experimentação do pensamento e num ethos de pesquisa, isto é, numa atitude ou caráter de pesquisar que estão mais próximos dos 
modos de ser e viver do pesquisador ou cartógrafo. "Com isso não se abre mão do rigor, mas esse é ressignificado. O rigor do caminho, sua precisão, está mais próximo dos movimentos da vida" (PASSOS; KASTRUP; ESCÓSSIA, 2012, p. 11).

Ao contrário dos métodos tradicionais, a cartografia "surgirá de modo mais ou menos imprevisível, sem que saibamos bem de onde. Para o cartógrafo, o importante é a localização de pistas, de signos de processualidade" (PASSOS; KASTRUP; ESCÓSSIA, 2012, p. 40). São essas pistas que orientam o percurso da pesquisa. Como não são hierárquicas, podemos iniciar o processo investigativo através de qualquer uma, tal como pode ser feito com o rizoma, que alude à estrutura de algumas plantas como a grama, cujos brotos se ramificam em qualquer ponto e se espalham sobre a superfície.

Sendo assim, os rizomas se regem pela composição de elementos variados e não podem ser reduzidos à unidade, por isso são tidos como múltiplos. Essa multiplicidade implica variadas linhas de força organizadas não hierarquicamente. Os rizomas fazem mapas, não decalques. Isso porque "um mapa tem múltiplas entradas contrariamente ao decalque que volta sempre 'ao mesmo' (DELEUZE; GUATTARI, 2011, p. 30). Em resumo, o rizoma é "oposto aos decalques, o rizoma se refere a um mapa que deve ser produzido, construído, sempre desmontável, conectável, reversível, modificável, com múltiplas entradas e saídas, com suas linhas de fuga" (DELEUZE; GUATTARI, 2011, p. 43).

Foi com base nesses princípios que regem os rizomas que criamos o mapa cartográfico da pesquisa. Nesse mapa, habitamos os territórios da mitologia grega, da indústria cultural e da educação visual através de três produções que apresentam a mitologia grega no século XXI, quais sejam: o livro, o filme e a graphic novel referentes à obra $O$ Ladrão de Raios, que é a primeira história da série Percy Jackson e os Olimpianos, escrita pelo norte-americano Rick Riordan.

Movidos pela história de aventura que perpassa essas produções e também por tantas outras inquietações, buscamos observar como se dá a passagem de uma obra literária para o cinema e os quadrinhos, as transformações do mito do herói e do monstro ocorridas desde a antiguidade até os tempos hodiernos e como estes personagens míticos foram apropriados pela indústria cultural. Observamos também quais as potencialidades educativas de $O$ Ladrão de Raios, ou seja, como os jovens estão interagindo com essa obra através do universo das narrativas transmídia, como eles estão sendo educados visualmente por elas e até que ponto estão expostos ao 
mero consumo de seu fluxo - daí, a necessidade de refletirmos a respeito de uma educação sobre/de/com os meios.

Para tanto, foi preciso habitar territórios, seguir pistas, lançar dispositivos dentro de outros dispositivos. Criar um tecido emaranhado por encontros e agenciamentos e dançar com essas linhas bailarinas. Desestabilizar e movimentar o pensamento do mesmo modo como fizeram Eduardo Passos, Virgínia Kastrup, Liliana da Escóssia, Marlucy Alves Paraíso, Thiago Ranniery Moreira Oliveira, Luciano Bedin da Costa, Suely Rolnik, dentre outros pesquisadores-cartógrafos cujas ideias "roubadas" se misturaram, diluíram-se e foram incorporadas à pesquisa e produção deste texto, direta e indiretamente. Tudo como se fosse uma grande conversa, pois "roubar é o contrário de plagiar, de copiar, de imitar ou de fazer como. A captura é sempre uma dupla-captura, o roubo, um duplo-roubo, e é isso que faz, não algo de mútuo, mas um bloco educador assimétrico, uma evolução a-paralela, núpcias, sempre 'fora' e 'entre"' (DELEUZE; PARNET, 1998, p. 6-7).

2. Os voos, os pousos, AS LINHAS... A CRIAÇÃO DE UM MAPA CARTOGRÁFICO

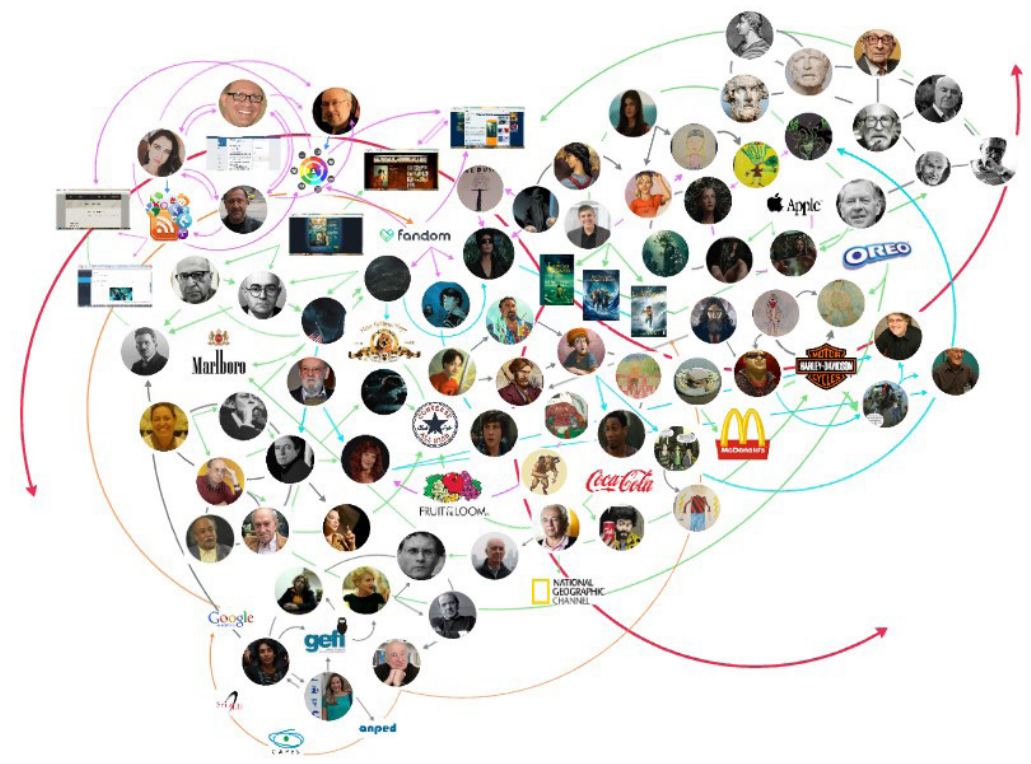

Fig. 1 - Mapa cartográfico (adaptado) - Fonte: GAVA, 2017, p. 125 
A imagem que trazemos nos possibilita ver que, embora uma pesquisa tenha como produtos algo material (dissertação, tese, artigo) seguindo um roteiro ordenado de leitura com introdução, desenvolvimento e conclusão, ela é construída entre linhas, dobras, conexões e rupturas, (des)enroladas num plano de experiência labiríntico conforme o pensamento rizomático de conhecimento.

Há uma trama de acontecimentos, conexões, ações, interações, retroações, determinações, acasos que envolvem os pesquisadores-cartógrafos, seus companheiros de aventura (em nosso caso, os personagens míticos), os diversos autores/ pensadores que emprestam as ferramentas (conceitos) para a construção e desconstrução da argumentação, dentre outros interlocutores que participam direta ou indiretamente de uma pesquisa. Assim, Percy Jackson e O Ladrão de Raios se tornou um espaço de encontros e agenciamentos que possibilitou a construção de um mapa das multiplicidades - mapa aberto, desmontável, reversível, sujeito a modificações permanentes, sempre com múltiplas entradas e saídas.

$\mathrm{O}$ que nos guiou dentro deste mapa foram algumas pistas e dispositivos. Segundo Passos, Kastrup e Escóssia (2012), as pistas orientam o percurso que devemos seguir na investigação, e os dispositivos, que serão mais bem explicados adiante, são "máquinas que fazem ver e falar" (p. 78). Dentre as muitas pistas que podem ser usadas numa cartografia e que são citadas por esses autores, foram utilizadas três: a pista da habitação de um território existencial, a da atenção do cartógrafo e a da política da narratividade.

Habitar um território corresponde a estarmos receptivos a ele e, consequentemente, deixar-nos impregnar por ele. A função da atenção não é de simples seleção de informação, mas detecção de forças circulantes dentro do território habitado. Para isso é necessário fazer voos e pousos, isto é, mudar de escala atencional diversas vezes. Já narrar, por sua vez, é dar voz aos afetos, é tornar visível tudo aquilo que é visto e sentido através das janelas atencionais. Assim, a narrativa cartográfica também se define como "política da narratividade", isto é, uma posição política e ética que tomamos quando, em relação ao mundo e a nós mesmos, definimos uma forma de expressão do que se passa, do que acontece (PASSOS; KASTRUP; ESCÓSSIA, 2012).

Ao habitar o território da mitologia grega por meio das produções escolhidas para a análise, nos colocamos em um movimento de atenção e em um gesto de observação, o que, como bem esclarece Passos, Kastrup e Escóssia (2012, p. 40), trata-se "de uma atitude de concentração pelo problema e no problema". Tendo em vista que queríamos descobrir como os produtos culturais, através das releituras, 
têm recriado imageticamente os deuses, heróis e seres mitológicos, nos colocamos em posição de observação e exploração cuidadosa do território habitado.

Num primeiro momento, buscamos nas produções relacionadas à obra $O$ Ladrão de Raios por aquilo que mais nos afetava, tentando não produzir compreensão imediata das coisas. A primeira coisa que nos chamou a atenção nas produções, sobretudo no filme, foi Tia Eme, a Medusa disfarçada. Sua aparência "monstruosamente bela" era o que mais nos encantava, além dela ser uma boa alegoria para falarmos de educação visual, do poder que as imagens têm para seduzir e prender o olhar das pessoas.

Atentas a essa personagem mítica, fizemos um gesto de pouso e buscamos reconfigurar o novo território que se abriu para nós. Quem era Medusa? Qual era o seu mito, sua iconografia e valor de culto? Por que ela havia nos afetado? Como ela aparecia no livro e na graphic novel? Na companhia dela, seguimos várias linhas durante a pesquisa. Buscamos conhecê-la, inicialmente, através das produções e percebemos que ela é o monstro que aparece mais vezes no filme. Sua história, nessa produção, difere-se da do livro e nem chega a aparecer na graphic novel publicada em português. A partir daí, buscamos conhecer na literatura clássica as variantes e o próprio mito de Medusa a fim de conferir se os símbolos e imagens da personagem mítica utilizados nas produções foram os mesmos descritos nas referências mais antigas.

$\mathrm{Na}$ cartografia, esse pouso que fizemos não deve ser entendido como uma parada "do" movimento de observar, mas uma parada "no", "dentro" do movimento de observar. O movimento é o que permite à atenção mudar de escala, de "janela" atencional. "Cada janela cria um mundo e cada uma exclui momentaneamente as outras, embora outros mundos continuem copresentes. Cada visada através de uma janela dá lugar, em sua escala, aos diversos gestos atencionais, possibilitando também mudanças de nível” (PASSOS; KASTRUP; ESCÓSSIA, 2012, p. 44).

Além de Medusa, outro personagem que nos chamou a atenção nas produções foi Percy Jackson. Não só porque é o protagonista, mas porque a ele todos os outros personagens se conectam. Além disso, ele é um personagem criado a partir dos conceitos clássicos do arquétipo de herói (no caso, de Perseu e outros heróis míticos gregos), mas, ao mesmo tempo, carrega em sua personalidade traços contemporâneos, tais como a dislexia e o Transtorno de déficit de atenção com hiperatividade (TDAH). Além disso, na literatura clássica os mitos de Medusa e Perseu se intercruzam, encontrando-se em vários pontos.

Se, inicialmente, pudemos ver as produções relacionadas à obra $O$ Ladrão de Raios a partir de uma janela-paisagem, panorâmica e cheia de elementos e 
personagens próximos e distantes passíveis de serem conectados, com o pouso pudemos vê-las a partir de uma janela-pátio. Essa janela é "típica das atividades de deslocamento e orientação. Envolve detecção e é preponderante na atividade do caçador" (PASSOS; KASTRUP; ESCÓSSIA, 2012, p. 44).

Como caçadoras, lançamos mão de dispositivos (as "máquinas que fazem ver e falar", ditas por Passos, Kastrup e Escóssia [2012, p. 78]), que são um conjunto multilinear, destacando linhas de natureza diferentes - linhas de visibilidade, de enunciação, de força e de subjetivação. Embora esse conceito de dispositivo já nos auxilie bastante a pensar nos deslocamentos que fizemos, uma outra definição de dispositivo também nos parece interessante:

qualquer coisa que tenha de algum modo a capacidade de capturar, orientar, determinar, interceptar, modelar, controlar e assegurar os gestos, as condutas, as opiniões e os discursos dos seres viventes. Não somente, portanto, as prisões, os manicômios, o panóptico, as escolas, as confissões, as fábricas, as disciplinas, as medidas jurídicas etc., cuja conexão com o poder é em um certo sentido evidente, mas também a caneta, a escritura, a literatura, a filosofia, a agricultura, o cigarro, a navegação, os computadores, os telefones celulares e - por que não - a linguagem mesma, que é talvez o mais antigo dos dispositivos, em que há milhares e milhares de anos um primata - provavelmente sem dar-se conta das consequências que se seguiriam - teve a inconsciência de se deixar capturar (AGAMBEN, 2005, p. 13).

Por essa definição de Giorgio Agamben é possível perceber que o livro, o filme e a graphic novel são dispositivos dentro de, ou permeados por outros dispositivos, como, por exemplo, a indústria cultural, os próprios meios de comunicação, as narrativas transmídia etc. É no desembaraçamento das linhas de visibilidade, de enunciação, de força e de subjetivação que compõem esses dispositivos que foi possível pensar a respeito da produção e do consumo de imagens ligados a um mercado do entretenimento, de bens e capitais simbólicos; a respeito, ainda, do conhecimento, da apropriação e da transmidiação dos mitos, das situações de aprendizagem mediadas pelas narrativas mitológicas presentes na cultura digital em suas mais diversas linguagens/ plataformas; e, também, sobre os novos processos de construção de subjetividades, os novos modos de viver, ser, conhecer, ensinar e aprender que proporcionam aos sujeitos diferentes "Educações", como nos diz Versuti, Scareli (2017). 
Para fazer funcionar e acompanhar os efeitos desses dispositivos, lançamos mão da decupagem, processo que consiste em capturar fotogramas e selecionar discursos do livro, filme e graphic novel. Refletindo melhor a respeito da decupagem, percebemos que ela é tanto um instrumento de produção de dados (intervenção que agencia sujeito e objeto) quanto um dispositivo (orienta as condutas, opiniões e os discursos). Com esse dispositivo-instrumento pudemos, então, descobrir as sutilezas dos personagens, como eles se apresentam nas produções, como foram recriados imageticamente pela indústria do entretenimento e em função de uma cultura do espetáculo.

No momento em que fizemos as decupagens, estávamos com vistas à janela-sala. Essa janela "permite a atenção dividida. Comporta focalização, mas também assimila uma multiplicidade de partes com graus de nitidez diferenciados" (PASSOS; KASTRUP; ESCÓSSIA, 2012, p. 44) - o que foi necessário para a pesquisa, já que pretendíamos com nossos companheiros de aventura (Medusa e Percy) fazer um retorno à Grécia arcaica, comparando os mitos desse tempo com os hodiernos, para descobrir se eles, ao longo do tempo, se profanaram ou foram adquirindo outras características para sobreviverem e se perpetuarem.

Depois de várias tentativas, como se estivéssemos querendo juntar e/ou separar as peças de um ou mais quebra-cabeças misturados, conseguimos seguir duas linhas para pensar com esses personagens míticos: uma sob o viés da produção de bens culturais para consumo e, consequentemente, produção de subjetividades que dela decorre, e outra sob o viés das próprias linguagens empregadas na construção desses bens, no caso, a literatura, o cinema e a história em quadrinhos, que também educa e também contribui para a produção de subjetividades. Subjetividades que não implicam uma posse, "mas uma produção incessante que acontece a partir dos encontros que vivemos com o outro" (MANSANO, 2009, p. 111). Na mesma direção, encontramos em Guattari; Rolnik (1996, p. 27) uma definição que auxilia muito a pensar na cartografia que estamos produzindo e nas subjetividades com que estamos lidando, e por que não, criando:

A subjetividade é produzida por agenciamentos de enunciação. Os processos de subjetivação, de semiotização - ou seja, toda a produção de sentido, de eficiência semiótica não são centrados em agentes individuais (no funcionamento de instâncias intrapsíquicas, egóicas, microssociais), nem em agentes grupais. Esses processos são duplamente descentrados. Implicam o funcionamento de máquinas de expressão que podem ser tanto de natureza extra-pessoal, extra-individual (sistemas maquínicos, econômicos, 
sociais, tecnológicos, icônicos, ecológicos, etológicos, de mídia, enfim sistemas que não são mais imediatamente antropológicos), quanto de natureza infra-humana, infrapsíquica, infrapessoal (sistemas de percepção, de sensibilidade, de afeto, de representação, de imagens, de valor, modos de memorização e produção de ideia, sistemas de inibição e de automatismos, sistemas corporais, orgânicos, biológicos, fisiológicos, etc.).

Com esse entendimento, como se estivéssemos fazendo um "zoom", passamos para a janela-página, "através da qual se faz uma entrada no campo perceptivo, seguida de movimentos de orientação, comportando indícios de distribuição da atenção" (PASSOS; KASTRUP; ESCÓSSIA, 2012, p. 44) e, por fim, para a janela micro, que funciona na escala da atividade do joalheiro, da bordadeira e do leitor minucioso. Segundo Passos, Kastrup e Escóssia (2012, p. 44), essa janela corresponde a um tipo de atenção "que se caracteriza por uma atividade eminentemente focal". Assim, a fim de produzir novos sentidos, buscamos "instrumentalizar" alguns conceitos pinçados de uma série de teorias, algumas delas, inclusive, que demonstram perspectivas distintas e que já vinham sendo acessadas ao longo da pesquisa, isso porque, para Rolnik (2011, p. 65) “teoria é sempre cartografia” e, para Deleuze (In: FOUCAULT, 2010, p. 71):

Uma teoria é como uma caixa de ferramentas. Nada tem a ver com o significante... É preciso que sirva, é preciso que funcione. E não para si mesma. Se não há pessoas para utilizá-la, a começar pelo próprio teórico que deixa então de ser teórico, é que ela não vale nada ou que o momento ainda não chegou. Não se refaz uma teoria, fazem-se outras; há outras a serem feitas. É curioso que seja um autor que é considerado um puro intelectual, Proust, que o tenha dito tão claramente: tratem meus livros como óculos dirigidos para fora e se eles não lhes servem, consigam outros, encontrem vocês mesmos seu instrumento, que é forçosamente um instrumento de combate. A teoria não totaliza; a teoria se multiplica e multiplica.

E se multiplicando, vão as teorias, os conceitos, os rizomas... os nossos estudos com as produções e os personagens escolhidos, longe de um fim conhecido. Um longo fio de Ariadne que, pouco a pouco, vai nos mostrando as entradas e as saídas deste labirinto de ideias em torno do mito, da indústria cultural e da educação visual. Uma pesquisa sempre em construção, cheia de conexões e rupturas, mas da qual podem ser mostrados alguns pontos, isto é, alguns conjuntos de linhas que compõem os rizomas do nosso mapa cartográfico, mapa das multiplicidades. O que percebemos através das diferentes 
janelas atencionais? O que vimos durante nossos voos e pousos? Para este texto, decidimos apresentar o que julgamos ser importante para a pesquisa em educação.

\section{Perseu e Medusa em O ladrão de Raios}

Através de fragmentos de textos, conjunto de planos, ângulos, movimentos de câmera e recursos de montagem que compõem o universo de um livro, um filme e uma graphic novel, buscamos observar como o herói e o monstro foram apropriados pela literatura, cinema e quadrinhos e como essas produções culturais nos dão a ver esses dois personagens míticos e suas representações com o passar do tempo. $\mathrm{Ou}$ seja, como Perseu foi transformado em Percy Jackson e Medusa em Tia Eme por meio do pastiche, que recorre tanto ao arquétipo do herói e do monstro clássicos, quanto ao estereótipo do estudante do século XXI.

No que tange a Percy Jackson, podemos perceber que o herói e protagonista da obra $O$ Ladrão de Raios derrota diversos monstros como a Medusa, o Minotauro e a Hidra (a depender da produção). Certamente, Perseu derrotou Medusa, mas o herói não chegou a enfrentar os outros dois monstros mencionados. Na mitologia grega, quem matou o Minotauro (criatura com cabeça, cauda e cascos de touro e corpo humano) foi Teseu, e a Hidra (serpente aquática de múltiplas cabeças), Hércules. Observa-se ainda que Percy matou uma cobra quando criança, tal como esse último herói fez na mesma idade. Quem não conhece um pouco de mitologia grega acaba crendo que todos esses feitos de Percy são derivados do mito de Perseu, quando na verdade são uma mistura de mitos e heróis.

Além disso, essa forma americanizada do mito compôs Percy e seus amigos com o estereótipo de um estudante do século XXI - estudante inserido no contexto da "cultura de consumo" ou "cultura-mercadoria". Em todas as produções, eles aparecem usando roupas casuais como jaquetas, blusas com capuz, camisetas estampadas, calças jeans, tênis do tipo All Star etc., adolescentes que consomem e se expressam por produtos/marcas mundialmente conhecidos, como Coca-Cola, McDonald's, MacBook, iPod, dentre outros mencionados na obra.

Há de se ressaltar também que, enquanto na literatura clássica é descrito que Perseu dispôs diante de si um polido escudo de bronze para evitar ser petrificado por Medusa, na obra $O$ Ladrão de Raios Percy se vale de seu iPod para enfrentar a criatura horripilante, marcando, assim, a inserção de elementos contemporâneos na narrativa 
mítica. Porém, esse aparelho aparece apenas na produção cinematográfica. No livro e na graphic novel, o garoto usa para o mesmo fim uma bola de vidro de jardim.

Já no que tange a Tia Eme, podemos notar que o arquétipo de monstro também sofreu alterações. A Medusa que a obra nos apresenta, camuflada de Tia Eme, é um pouco diferente do que a literatura clássica descreve; ela não deixa, no entanto, de ser interessante. Em sua primeira aparição no filme, a dona da loja de jardinagem surge como uma mulher de meia-idade, magra, alta e de pele branca. Ela está vestindo um sobretudo de couro e, por baixo desse sobretudo, calça e blusa muito bem ajustadas. Seu rosto e colo estão à mostra, mas ela usa lenço, óculos e luvas para encobrir seus cabelos, olhos e mãos.

Tia Eme aparece com as roupas e acessórios pretos não só no filme, mas também na graphic novel e no livro. Essa cor está associada ao mistério, à escuridão, às coisas escondidas, ao terror e à morte, sugerindo também a introversão, a reclusão. Ela alude ao comportamento ofídico de Medusa se esconder, camuflar-se e tornar-se ferozmente agressiva quando ameaçada. Também alude a sua perversidade, pois Medusa tira as vidas das pessoas com um simples olhar. A cor denota, ainda, tristeza e faz alusão ao ressentimento de Medusa por ter sido transformada em monstro e por ter perdido a beleza de seus admiráveis cabelos.

Exceto a cor, o estilo da roupa e o sotaque de Medusa nos possibilitam pensar que Riordan esteja fazendo referência a países do Oriente Médio, que estavam em conflito com os EUA e por eles são considerados hostis. Países que causam o "terror" tanto no seu próprio território quanto nos territórios vizinhos e sobre os quais a metáfora do "monstro" vir vestido de burca cai bem. Medusa é descrita/aparece de burca apenas no livro e na graphic novel. Essa é uma releitura notoriamente feita conforme a época e cultura do autor americano.

Sem as roupas que a camuflam, Medusa aparece nas três produções tal como a literatura clássica descreve: com a cabeleira eriçada de serpente, os olhos arregalados e flamejantes. Mas, enquanto no livro e na graphic novel Medusa aparece com a pele esverdeada e com garras ou unhas, no filme ela aparece com a pele branca e as mãos normais, sobretudo, bem cuidadas. Nota-se que aquilo que na literatura causa horror, no cinema torna-se objeto de beleza.

Com Percy e Tia Eme podemos perceber que tanto o herói quanto o monstro não são personagens estáticos; ao contrário, suas visualidades mudam com o passar do tempo, conforme a sociedade e a cultura se transformam. Os monstros estão presentes em todas as culturas, em especial, na imaginação das crianças. Essencialmente 
arraigados aos nossos medos, eles expressam uma diversidade enorme de temores humanos. Já o herói continua sendo importante para humanizar as narrativas, provocar a identificação com elas e boas doses de entretenimento e catarse - elementos fundamentais para o nosso bem-estar e reflexão sobre a vida e sobre os nossos medos.

\section{Para (Não) CONCluir}

Após esses voos e pousos e $(\mathrm{m})$ diferentes janelas atencionais, consideramos importante destacar que a produção de dados, na perspectiva cartográfica, ocorre desde a etapa inicial da pesquisa. Como bem esclarece Passos, Kastrup e Escóssia (2012, p. 48), "esse processo continua em etapas posteriores, atravessando as análises subsequentes dos dados e a escrita de textos, continuando ainda com a publicação dos resultados". Isso nos permite reafirmar que a cartografia como método de pesquisa em educação "surge como uma possibilidade de pesquisa que vem crescendo muito, uma prática investigativa que, ao invés de buscar um resultado ou conclusão, procura acompanhar o processo" (COSTA, 2014, p. 70). Trata-se, pois, de um modo próprio e inventivo de pesquisar: primeiro, porque respeita os interesses do pesquisador, bem como todos os atravessamentos que o perpassam; segundo, porque seu caráter inventivo "coloca a ciência em constante movimento de transformação, não apenas refazendo seus enunciados, mas criando novos problemas e exigindo práticas originais de investigação" (PASSOS; KASTRUP; ESCÓSSIA, 2012, p. 56).

Por assim ser, e romper com a estrutura de conhecimento tradicional, a cartografia nos permitiu experimentar a nossa própria pesquisa. Mais que capturar e analisar discursos e imagens, nos permitiu fluir e fruir "com" eles. Assim, no lugar de "o que é isto que vejo", nos perguntamos: "como eu estou compondo com isto que vejo”. Mudança paradigmática que nos permitiu perceber, através das janelas atencionais, que a obra $O$ Ladrão de Raios, um produto cultural massificado a princípio, que poderia ser qualificado como sem relevância para a educação, também educa. Ela nos proporciona reflexões em torno de inúmeras questões voltadas para a mitologia grega, a sociedade contemporânea, a produção de bens culturais, a cultura de massa, a espetacularização da realidade, o consumo (principalmente de imagens), a mídia-educação etc. - temas que são objetos de pesquisa de diversos trabalhos acadêmicos, incluindo a dissertação da qual este artigo é fruto.

Essas são só algumas possibilidades observadas e destacadas durante os nossos voos e pousos para pensarmos neste artigo, mas inúmeras outras podem ser 
pensadas a partir da obra. Com base no pensamento rizomático, reconhecemos que o conhecimento por completo é inatingível. Ele sempre estará inacabado, podendo ser, a qualquer momento, aumentado, interrogado. Por esse motivo, esta pesquisa não pode ser considerada um trabalho conclusivo. Muito ainda está por ser feito e outros, inúmeros outros sentidos podem ser cartografados no que diz respeito à relação entre mito, produtos culturais e educação visual.

\section{REFERÊNCIAS}

AGAMBEN, Giorgio. O que é um dispositivo? Rev. Outra Travessia. Trad. Nilceia Valdati. Ilha de Santa Catarina, $2^{\circ}$ semestre de 2005. Disponível em: https://periodicos.ufsc.br/index.php/ Outra/article/view/12576. Acesso em: 24 de maio de 2017.

COSTA, Luciano Bedin da. Cartografia: uma outra forma de pesquisar. Revista Digital do LAV, Santa Maria, v. 7, n. 2, p. 66-77, mai./ago. 2014. Disponível em: https://periodicos.ufsm.br/revislav/ article/view/15111. Acesso em: 30 de março de 2020.

DELEUZE, Gilles; GUATTARI, Félix. Mil Platôs: capitalismo e esquizofrenia. Rio de Janeiro: Ed. 34, 1995. (v. 1, versão em PDF)

DELEUZE, Gilles; GUATTARI, Félix. Mil Platôs: capitalismo e esquizofrenia. v. 1. 2. ed. Rio de Janeiro: Ed. 34, 2011.

DELEUZE, Gilles; PARNET, Claire. Diálogos. Trad. Eloisa Araújo Ribeiro, São Paulo: Escuta, 1998. FOUCAULT, Michel. Microfísica do poder. Org. e Trad. Roberto Machado. Rio de Janeiro: Edições Graal, 2010.

GALLO, Sílvio. Deleuze e a Educação. Belo Horizonte: Autêntica Editora, 2013.

GUATTARI, Félix; ROLNIK, Sueli. Micropolítica: cartografias do desejo. Petrópolis, RJ: Vozes, 1996. KASTRUP, Virgínia; PASSOS, Eduardo. Cartografar é traçar um plano comum. Fractal, Rev. Psicol., v. 25, n. 2, p. 263-28o, maio/ago., 2013.

MANSANO, Sonia R. V. Sujeito, subjetividade e modos de subjetivação na contemporaneidade. Revista de Psicologia da UNESP, 8 (2). 2009. Disponível em: http://seer.assis.unesp.br/index. $\mathrm{php} / \mathrm{psicologia/article/view/946.} \mathrm{Acesso} \mathrm{em:} 30$ de março de 2020.

MORIN, Edgar. Introdução ao pensamento complexo. Trad. Eliane Lisboa. Porto Alegre: Ed. Sulina, 2015. PASSOS, Eduardo; KASTRUP, Virgínia; ESCÓSSIA, Liliana da (Org.). Pistas do método da cartografia: pesquisa-intervenção e produção de subjetividade. Porto Alegre: Sulina, 2012.

ROLNIK, Suely. Cartografia Sentimental: transformações contemporâneas do desejo. Porto Alegre: Sulina, 2011.

VERSUTI, Andrea; SCARELI, Giovana. Direito a Educação ou Educações? $38^{a}$ Reunião Nacional da ANPEd. 2017. São Luís/MA. P. 1-16. Anais... Disponível em: http://anais.anped.org.br/sites/ default/files/arquivos/trabalho_38anped_2017_GT12_146.pdf. Acesso em: 30 de março de 2020. 
Sobre AS AUtoras.

Sabrina da Silva Gava. Mestre em Educação pela Universidade Federal de São João del-Rei (2017) e licenciada em Filosofia pela mesma instituição (2014). Foi bolsista do Programa de Educação Tutorial (PET-Filosofia) entre os anos de 2010 e 2011, bolsista de monitoria da disciplina de Estágio Curricular Supervisionado entre os anos de 2013 e 2014 e bolsista de Iniciação Científica do Programa Institucional de Bolsas de Iniciação Científica (PIBIC) entre os anos de 2014 e 2015. Integra o Grupo de Pesquisa em Educação, Filosofia e Imagem (GEFI/ UFSJ) e desenvolve, desde então, pesquisas na área de educação visual com ênfase nos seguintes temas: mitologia grega, indústria cultural e narrativas transmídias. Tem formação complementar ligada as áreas de Tutoria em Educação à Distância (2013-2014) e de Assistência Administrativa (2017-2018). Atualmente, é graduanda em Administração no Instituto Federal de Educação, Ciência e Tecnologia do Sudeste de Minas Gerais.

E-mail: sabrinasgava@hotmail.com.

Giovana Scareli. Doutora em Educação na Área de Concentração: Educação, Conhecimento, Linguagem e Arte pela Universidade Estadual de Campinas Unicamp (2009). Mestre em Educação pela Unicamp (2003) e Graduada em Pedagogia também pela Unicamp (1999). Realizou pós-doutorado na área de Educação, junto ao Programa de Pós-Graduação em Educação da Universidade Federal de Santa Catarina - UFSC, com missões de estudo no Instituto de Geografia da Universidade de Buenos Aires e no Instituto de Filosofia da Universidade Nova de Lisboa. Tem experiência na área de Educação, atuando principalmente nos seguintes temas: educação, imagem, literatura, cinema, desenho infantil, filosofia e arte-educação. É Professora do Departamento de Ciências da Educação da Universidade Federal de São João del-Rei - DECED/ UFSJ, pesquisadora do Programa de Pós-Graduação - Mestrado em Educação da UFSJ e Líder do Grupo de Pesquisa em Educação, Filosofia e Imagem - GEFI/ UFSJ, certificado pelo CNPq. E-mail: gscareli@yahoo.com.br.

Recebido em 13 de abril de 2020 e aprovado em 25 de maio de 2021. 